\title{
"The Nonlinear Dynamic Relationship of Exchange Rates: Parametric and Nonparametric Causality testing”
}

\author{
Stelios D. Bekiros*, Cees G.H Diks \\ CeNDEF, Department of Quantitative Economics, University of Amsterdam, \\ Roetersstraat 11, 1018 WB Amsterdam, The Netherlands
}

\begin{abstract}
The present study investigates the long-term linear and nonlinear causal linkages among six currencies, namely EUR/USD, GBP/USD, USD/JPY, USD/CHF, AUD/USD and $\mathrm{USD} / \mathrm{CAD}$. The prime motivation for choosing these exchange rates comes from the fact that they are the most liquid and widely traded, covering about $90 \%$ of total FX trading worldwide. The data spans two periods (PI: 3/20/1991 - 3/20/1997, PII: 3/20/2003 $3 / 20 / 2007$ ) before and after the structural break of the Asian financial crisis, which set a platform for departure for causality testing. We apply a new nonparametric test for Granger non-causality by Diks and Panchenko $(2005,2006)$ as well as the conventional linear Granger test on the return time series. To ensure that any causality is strictly nonlinear in nature, we also examine the nonlinear causal relationships of pairwise VAR filtered residuals as well as in a six-variate formulation. We find remaining significant biand uni-directional causal nonlinear relationships in the return series. Finally, we investigate the hypothesis of nonlinear non-causality after controlling for conditional heteroskedasticity in the data using a GARCH-BEKK model. Our approach allows the entire variance-covariance structure of the currency interrelationship to be incorporated in order to explicitly capture the volatility spillover mechanism. Whilst the nonparametric test statistics are smaller in some cases, significant nonlinear causal linkages persisted even after GARCH filtering during both the pre- and post-Asian crisis period. This indicates that currency returns may exhibit asymmetries and statistically significant higher-order moments.
\end{abstract}

JEL classification: C14; C51; F31

Keywords: Nonparametric Granger causality; foreign exchange; spillovers; VAR filtering; GARCH-BEKK

*E-mail address: S.Bekiros@uva.nl (corresponding author); Tel.: + 3120525 5375; fax.: + 31205255283. 


\section{Introduction}

In the nineties the gradual abolition of capital controls and trade barriers provided the foundation for liberalized and deregulated financial markets. This less restrictive environment created a systematic interrelationship between and within the stock and currency markets. Specifically, foreign exchange markets have grown fiscally and monetarily (i.e. by achieving lower inflation and/or interest rate differentials) more similar, which generally led to lower exchange rate volatility and caused asymmetry in reactions toward macroeconomic developments to significantly decrease (Laopodis, 1998). This growing similarity may also reflect a temporary, or long-term, causal relationship between the major currency markets. A rich empirical literature exists on the propagation mechanism (spillovers) of US currency volatility across other foreign exchange markets and on "stylized facts" like leptokurtosis and volatility clustering. These studies focus on the investigation of the stochastic behavior of the US dollar, mostly employing the autoregressive conditional heteroskedastic ( $\mathrm{ARCH})$ methodology of Engle (1982) (Engle and Bollerslev, 1986; Boothe and Glassman, 1987; Hsieh, 1989; Baillie and Bollerslev, 1989, 1990; Engle et al., 1990). The nature of the volatility transmission mechanism as well as the degree of price information efficiency was investigated in the beginning of the higher integration of foreign exchange rates vis-à-vis the US dollar (Hogan and Sharpe, 1984; Ito and Roley, 1987). Some empirical evidence by Koutmos and Booth (1995) and Laopodis (1997) suggests that the size and/or sign of an innovation in US exchange rates may seriously affect the extent of dependence and spillovers across markets. Given the status of the USD as the anchor currency, it should be interesting to examine its volatility transfers and more general the nature of causal 
linkages with other major currencies. If these exist, it would suggest that on a global scale, news originating in a specific market is fully and efficiently transmitted to other foreign markets, thereby providing support to the "meteor shower" notion coined by Engle et al. (1990). This term applies to a situation where volatility originating in one market flows over other markets, as opposed to the term "heat wave" also introduced by Engle et al. (1990) which suggests that volatility would continue in the originating market the next day or that it is country-specific.

The nature of causality in currency markets, i.e. linear or nonlinear is also a matter for investigation. Ever since the influential work of Meese and Rogoff (1983) in which they examined the failure of some linear exchange rate models, several more recent studies have provided further evidence of the empirical failure of the linear models (Flood and Rose, 1995; Rose, 1996). The theoretical extension of the linear exchange rate framework to nonlinear models has been growing in the literature. According to Ma and Kanas (2000) these nonlinear extensions include the concept of bubbles with selffulfilling expectations (Flood and Garber, 1980; Blanchard and Watson, 1982; Froot and Obstfeld, 1991), target zone models (Krugman, 1991), models of micro-foundation of trading behaviour (Krugman and Miller, 1993), nonlinear monetary policies (Flood and Isard, 1989), and noise trading (Shiller, 1984; Kyle, 1985; Black, 1986; Frankel and Froot, 1986; Summers, 1986; De Long et al., 1990). Empirical studies have mainly tested for nonlinearities due to target zones, and have failed to support such nonlinearities (Meese and Rose, 1990; and Flood et al., 1991; Lindberg and Soderlind, 1994). It still remains an open question whether these or other types of nonlinear interdependencies across currency markets exist. 
The recent empirical evidence is invariably based on the linear Granger causality test (Granger, 1969). The conventional approach of testing for Granger causality is to assume a parametric, linear time series model for the conditional mean. This approach is appealing, since the test reduces to determining whether the lags of one variable enter into the equation for another variable, although it requires the linearity assumption. Moreover, tests based on residuals will be sensitive only to causality in the conditional mean while covariables may influence the conditional distribution of the response in nonlinear ways. Additionally, Baek and Brock (1992) noted that parametric linear Granger causality tests have low power against certain nonlinear alternatives. In view of this, nonparametric techniques are appealing because they place direct emphasis on prediction without imposing a linear functional form. Various nonparametric causality tests have been proposed in the literature. The test by Hiemstra and Jones (1994) which is a modified version of the Baek and Brock (1992) test is regarded as a test for a nonlinear dynamic relationship. This test can detect the nonlinear Granger-causal relationship between variables by testing whether the past values influence present and future values. However, Diks and Panchenko $(2005,2006)$ demonstrate that the Hiemstra and Jones test can severely over-reject if the null hypothesis of non-causality is true, i.e., the Hiemstra and Jones test has serious size distortion problems. As an alternative Diks and Panchenko (2006) developed a new test statistic that overcomes these limitations. Their empirical results suggest that some of the rejections of the Granger non-causality hypothesis, using the Hiemstra and Jones test, may be spurious.

The aim of the current paper is to test for the existence of both linear and nonlinear causal relationships among six currencies, namely EUR/USD, GBP/USD, 
USD/JPY, USD/CHF, AUD/USD and USD/CAD. The prime motivation for choosing these exchange rates (also known as "FX majors") comes from the fact that they are the most liquid and widely traded currency pairs in the world. Trades involving "majors" make up about $90 \%$ of total Forex trading worldwide. The data cover a pre- and a postAsian crisis period. The Asian crisis started with a $15-20 \%$ devaluation of Thailand's Bath which took place on July 2, 1997. Subsequently it was followed by devaluations of the Philippine Peso, the Malaysian Ringgit, the Indonesian Rupiah and the Singaporean Dollar. In addition, the currencies of South Korea and Taiwan suffered. Further in October, 1997 the Hong Kong stock market collapsed with a 40\% loss. In January 1998, the currencies of most South-East Asian countries regained parts of the earlier losses. In that context, it is worth investigating whether the time period after the 1997 Asian financial crisis may have changed the direction and strength of the causal relationships among the currencies under study.

In the present study we apply a three-step empirical framework for examining dynamic relationships among foreign exchange markets. First, we explore linear and nonlinear dynamic linkages between exchange rates, applying both a parametric Granger causality test and the nonparametric Diks-Panchenko causality test. Then, after filtering return series pairwise, as well as in a six-variate formulation for linear Vector AutoRegressive (VAR) structure, the series of residuals are examined pairwise by the nonparametric Diks-Panchenko causality test. This step ensures that any remaining causality is strictly nonlinear in nature, as the VAR model has already purged the residuals of linear causality. Finally, in the last step, we investigate the hypothesis of nonlinear non-causality after controlling for conditional heteroskedasticity in the data 
using a GARCH-BEKK model again, both pairwise and in a six-variate representation. Our approach allows the entire variance-covariance structure of the currency interrelationship to be incorporated. The empirical methodology employed with the multivariate GARCH-BEKK model can help not only to understand the short-run movements but also explicitly capture the volatility spillover mechanism. The method's advantage rests with its ability to examine all markets concurrently and paired, assuming that spillovers are realizations of a process of international news affecting the examined markets. Improved knowledge of the direction and nature of causality and interdependency between the currency markets and consequently the degree of their integration will expand the information set available to international portfolio managers, multinational corporations, and policymakers for decision-making.

The remainder of the paper is organized as follows. Section 2 briefly reviews the linear Granger causality framework and provides a description of the Diks-Panchenko nonparametric test for nonlinear Granger causality. Section 3 describes the data used and Section 4 presents the results. Section 5 concludes with suggestions for future research.

\section{The Nonparametric Diks - Panchenko Causality Test}

Granger (1969) causality has turned out to be a useful notion for characterizing dependence relations between time series in economics and econometrics. Assume that $\left\{X_{t}, Y_{t} ; t \geq 1\right\}$ are two scalar-valued strictly stationary time series. Intuitively $\left\{X_{t}\right\}$ is a strictly Granger cause of $\left\{Y_{t}\right\}$ if past and current values of $X$ contain additional information on future values of $Y$ that is not contained only in the past and current $Y_{t}$ values. Let $F_{X, t}$ and $F_{Y, t}$ denote the information sets consisting of past observations of 
$X_{t}$ and $Y_{t}$ up to and including time $t$, and let ' $\sim$ ' denote equivalence in distribution. Then $\left\{X_{t}\right\}$ is a Granger cause of $\left\{Y_{t}\right\}$ if, for $k \geq 1$ :

$$
\left(Y_{t+1}, \ldots, Y_{t+k}\right)\left|\left(F_{X, t}, F_{Y, t}\right) \nsim\left(Y_{t+1}, \ldots, Y_{t+k}\right)\right| F_{X, t}
$$

In practice $k=1$ is used most often, i.e. testing for Granger non-causality comes down to comparing the one-step-ahead conditional distribution of $\left\{Y_{t}\right\}$ with and without past and current observed values of $\left\{X_{t}\right\}$. A conventional approach of testing for Granger causality is to assume a parametric, linear, time series model for the conditional mean $E\left(Y_{t+1} \mid\left(F_{X, t}, F_{Y, t}\right)\right)$. Then, causality can be tested by comparing the residuals of a fitted Autoregressive model of $Y_{t}$ with those obtained by regressing $Y_{t}$ on infinite past values of both $\left\{X_{t}\right\}$ and $\left\{Y_{t}\right\}$ (Granger, 1969). Now, assume delay vectors $\mathbf{X}_{t}^{\ell_{X}}=\left(X_{t-\ell_{X}+1}, \ldots, X_{t}\right)$ and $\mathbf{Y}_{t}^{\ell_{Y}}=\left(Y_{t-\ell_{Y}+1}, \ldots, Y_{t}\right),\left(\ell_{X}, \ell_{Y} \geq 1\right)$. In practice the null hypothesis that past observations of $\mathbf{X}_{t}^{\ell_{X}}$ contain no additional information (beyond that in $\mathbf{Y}_{t}^{\ell_{Y}}$ ) about $Y_{t+1}$ is tested, i.e.:

$$
H_{0}: Y_{t+1}\left|\left(\mathbf{X}_{t}^{\ell_{X}} ; \mathbf{Y}_{t}^{\ell_{Y}}\right) \sim Y_{t+1}\right| \mathbf{Y}_{t}^{\ell_{Y}}
$$

For a strictly stationary bivariate time series Eq. (2) comes down to a statement about the invariant distribution of the $\left(\ell_{X}+\ell_{Y}+1\right)$-dimensional vector $\mathbf{W}_{t}=\left(\mathbf{X}_{t}^{\ell_{X}}, \mathbf{Y}_{t}^{\ell_{X}}, Z_{t}\right)$ where $Z_{t}=Y_{t+1}$. To keep the notation compact, and to bring about the fact that the null hypothesis is a statement about the invariant distribution of $\left(\mathbf{X}_{t}^{\ell_{x}}, \mathbf{Y}_{t}^{\ell_{x}}, Z_{t}\right)$ we drop the time index and also $\ell_{X}=\ell_{Y}=1$ is assumed. Hence, under the null, the conditional distribution of $Z$ given $(X, Y)=(x, y)$ is the same as that of $Z$ given $Y=y$. Further, Eq. (2) 
can be restated in terms of ratios of joint distributions. Specifically, the joint probability density function $f_{X, Y, Z}(x, y, z)$ and its marginals must satisfy the following relationship:

$$
\frac{f_{X, Y, Z}(x, y, z)}{f_{Y}(y)}=\frac{f_{X, Y}(x, y)}{f_{Y}(y)} \cdot \frac{f_{Y, Z}(y, z)}{f_{Y}(y)}
$$

This explicitly states that $X$ and $Z$ are independent conditionally on $Y=y$ for each fixed value of $y$. Diks and Panchenko (2006) show that this reformulated $H_{0}$ implies:

$$
q \equiv E\left[f_{X, Y, Z}(X, Y, Z) f_{Y}(Y)-f_{X, Y}(X, Y) f_{Y, Z}(Y, Z)\right]=0
$$

Let $\hat{f}_{W}\left(W_{i}\right)$ denote a local density estimator of a $d_{W}$ - variate random vector $\mathbf{W}$ at $W_{i}$ defined by $\hat{f}_{W}\left(W_{i}\right)=\left(2 \varepsilon_{n}\right)^{-d_{W}}(n-1)^{-1} \sum_{j, j \neq i} I_{i j}^{W}$ where $I_{i j}^{W}=I\left(\left\|W_{i}-W_{j}\right\|<\varepsilon_{n}\right)$ with $I(\cdot)$ the indicator function and $\varepsilon_{n}$ the bandwidth, depending on the sample size $n$. Given this estimator, the test statistic is the sample version of Eq. (4):

$$
T_{n}\left(\varepsilon_{n}\right)=\frac{n-1}{n(n-2)} \cdot \sum_{i}\left(\hat{f}_{X, Z, Y}\left(X_{i}, Z_{i}, Y_{i}\right) \hat{f}_{Y}\left(Y_{i}\right)-\hat{f}_{X, Y}\left(X_{i}, Y_{i}\right) \hat{f}_{Y, Z}\left(Y_{i}, Z_{i}\right)\right)
$$

For $\ell_{X}=\ell_{Y}=1$, if $\varepsilon_{n}=C n^{-\beta}\left(C>0, \frac{1}{4}<\beta<\frac{1}{3}\right)$ then Diks and Panchenko (2006) prove under strong mixing that the test statistic in Eq. (5) satisfies:

$$
\sqrt{n} \frac{\left(T_{n}\left(\varepsilon_{n}\right)-q\right)}{S_{n}} \stackrel{D}{\rightarrow} N(0,1)
$$

where $\stackrel{D}{\rightarrow}$ denotes convergence in distribution and $S_{n}$ is an estimator of the asymptotic variance of $T_{n}(\cdot)$ (Diks and Panchenko, 2006). 


\section{Data and preliminary analysis}

The data consist of six time series of daily closing (5 days) foreign exchange rates, namely EUR/USD, GBP/USD, USD/JPY, USD/CHF, AUD/USD and USD/CAD. These are the most liquid and widely traded currency pairs in the world and make up about $90 \%$ of total Forex trading worldwide. The data cover two periods, before and after a structural break, which sets a platform for departure for causality tests. The first period PI spans from March 20, 1991 to March 20, 1997, denoting a pre-Asian crisis period (1567 observations), and the second PII, a post-Asian crisis period, from March 20, 2003 to March 20, 2007 (1044 observations). Recall that the on-set of the Asian financial crisis started with the devaluation of Thailand's Bath which took place on July 2, 1997 and followed by devaluations of the Philippine Peso, the Malaysian Ringgit, the Indonesian Rupiah, the Singaporean Dollar and in October, 1997 the Hong Kong stock market collapsed with a 40\% loss. In January 1998, the currencies of South-East Asian countries began to regain part of the earlier losses.

Descriptive statistics for both periods are reported in Table 1. Figure 1 displays the currency time series. The results from testing nonstationarity are presented in Table 2 .

\section{[ Insert Table 1 here ] \\ [ Insert Figure 1 here ] \\ [ Insert Table 2 here ]}

Specifically, Table 2 reports the Augmented Dickey-Fuller (ADF) test for the logarithmic levels and log-daily returns $r_{t}=\ln \left(P_{t}\right)-\ln \left(P_{t-1}\right)$, where $P_{t}$ is the closing price of the currency on day $t$. The appropriate lag lengths were selected using the Schwartz Information Criterion (SIC). All the variables appear to be nonstationary in log-levels and 
stationary in log-returns based on the reported $p$-values. Table 1 also reports the sample cross-correlation matrix at lag 0 (contemporaneous correlation) for both periods. The results indicate that in the pre-crisis period (PI), EUR/USD, GBP/USD, USD/JPY and USD/CHF are pairwise significantly positively or negatively correlated. Moreover, in PII (post-crisis period) significant sample cross-correlations are noted for all currencies (now including AUD/USD and USD/CAD) indicating higher integration of foreign exchange rates vis-à-vis the US dollar and strong bi-directional links among all markets. However, since linear correlations cannot fully capture the long-term dynamic linkages between the exchange rates in a reliable way, these results should be interpreted with caution. Consequently, what is needed is a long-term causality analysis of the currencies.

\section{Empirical results}

The empirical methodology comprises three steps. In the first pre-filtering step, we explore the linear and nonlinear dynamic linkages applying both a Granger causality test and the nonparametric Diks-Panchenko test on the raw log-differenced time series of the currencies. Then, we implement both bi-variate and six-variate VAR filtering on the return series and the residuals are examined pairwise by the Diks-Panchenko test. Finally, we investigate the hypothesis of nonlinear non-causality after controlling for conditional heteroskedasticity using a GARCH-BEKK filter again pairwise as well as in a six-variate representation. Additionally, in the last two steps we consistently apply a linear Granger causality test on the "whitened" residuals in order to investigate whether any remaining causality is strictly nonlinear in nature or not. 
The results are reported in the corresponding columns of Tables 3 and 4. In order to overcome the difficulty of presenting large tables with numbers we use the following simplifying notation: " $* *$ " indicating that the corresponding $p$-value of a particular causality test is smaller than $1 \%$ and " * " that the corresponding $p$-value of a test is in the range 1-5\%; Directional causalities will be denoted by the functional representation $\rightarrow$.

\subsection{Causality testing on raw returns}

The linear Granger causality test is usually constructed in the context of a reduced-form vector autoregression $(\mathrm{VAR})$. Let $\mathbf{Y}_{t}$ the vector of endogenous variables and $\ell$ number of lags. Then the $\operatorname{VAR}(\ell)$ model is given as follows:

$$
\mathbf{Y}_{t}=\sum_{s=1}^{\ell} \mathbf{A}_{s} \mathbf{Y}_{t-s}+\boldsymbol{\varepsilon}_{t}
$$

where $\mathbf{Y}_{t}=\left[Y_{1 t}, \ldots, Y_{\ell t}\right]$ the $\ell \times 1$ vector of endogenous variables, $\mathbf{A}_{s}$ the $\ell \times \ell$ parameter matrices and $\boldsymbol{\varepsilon}_{t}$ the residual vector, for which $E\left(\boldsymbol{\varepsilon}_{t}\right)=\mathbf{0}, E\left(\boldsymbol{\varepsilon}_{t} \boldsymbol{\varepsilon}_{s}^{\prime}\right)=\left\{\begin{array}{ll}\boldsymbol{\Sigma}_{\varepsilon} & t=s \\ \mathbf{0} & t \neq s\end{array}\right\}$. Specifically, in case of two stationary time series $\left\{X_{t}\right\}$ and $\left\{Y_{t}\right\}$ the bivariate VAR model is given by:

$$
\begin{aligned}
& X_{t}=A(\ell) X_{t}+B(\ell) Y_{t}+\varepsilon_{X, t} \quad t=1,2, \ldots, N \\
& Y=C(\ell) X_{t}+D(\ell) Y_{t}+\varepsilon_{Y, t}
\end{aligned}
$$

where $A(\ell), B(\ell), C(\ell)$ and $D(\ell)$ are all polynomials in the lag operator with all roots outside the unit circle. The error terms are separate i.i.d. processes with zero mean and constant variance. The test whether $Y$ strictly Granger causes $X$ is simply a test of the joint restriction that all the coefficients of the lag polynomial $B(\ell)$ are zero, whilst 
similarly, a test of whether $X$ strictly Granger causes $Y$ is a test regarding $C(\ell)$. In each case, the null hypothesis of no Granger causality is rejected if the exclusion restriction is rejected. If both $B(\ell)$ and $C(\ell)$ joint tests for significance show that they are different from zero, the series are bi-causally related. For each of the six raw return series linear causality testing was carried out using the Granger's test. The lag lengths of the VAR specification were selected using the Schwartz Information Criterion (SIC), which are presented in Tables 3, 4 in parentheses. For the Diks-Panchenko test, in what follows we discuss results for lags $\ell_{X}=\ell_{Y}=1$. To implement the test, the constant $C$ for the bandwidth $\varepsilon_{n}$ was set at 7.5 , which is close to the value 8.0 for $\mathrm{ARCH}$ processes suggested by Diks and Panchenko (2006). With the theoretical optimal rate $\beta=2 / 7$ given by DP (2006), this implies a bandwidth value of approximately 1 , for both PI and PII. Selected bandwidth values smaller (larger) than 1 resulted, in general, in larger (smaller) $p$-values.

The results presented in Tables 3 and 4 allow for the following observations: GBP/USD, USD/JPY, USD/CHF and AUD/USD linearly cause EUR/USD with small differences in PI and PII as well as regarding the degree of statistical significance. None of the currencies Granger causes GBP/USD. Further, there is a strong causal relationship which affects USD/JPY, USD/CHF, AUD/USD and USD/CAD, with USD/JPY Granger causing the others. Finally, USD/CHF presents a significant unidirectional linear relationship USD/CHF $\rightarrow \mathrm{USD} / \mathrm{CAD}$ in PII. AUD/USD and USD/CAD appear to lack any causal relationship. We next discuss the results for the Diks-Panchenko test. Interestingly starting form the latter example, in period PI, there is now strong evidence of bidirectional nonlinear relationship AUD/USD $\leftrightarrow$ USD/CAD. Any of the previously 
detected linear causality among USD/JPY, USD/CHF, AUD/USD and USD/CAD has vanished with the exception of a unidirectional nonlinear relationship $\mathrm{USD} / \mathrm{JPY} \leftarrow \mathrm{USD} / \mathrm{CAD}$ in both periods. Again none of the currencies causes GBP/USD. Only in PI, GBP/USD causes USD/CHF and the same currency causes AUD/USD in PII. Finally, strong nonlinear causality appears from others currencies toward EUR/USD but it no longer exists for AUD/USD and USD/CAD.

\section{[ Insert Table 3 here ]}

[ Insert Table 4 here ]

\subsection{Causality testing on VAR-filtered residuals}

The results from the previous step suggest that there are some significant and persistent linear and nonlinear causal linkages between the FX rates. However, even though we found nonlinear causality, the Diks-Panchenko test should be reapplied to filtered VAR-residuals to ensure that any causality found is strictly nonlinear in nature. The lag lengths of the VAR specification were based on the Schwartz Information Criterion (SIC). Moreover, a linear Granger test is applied to the filtered residuals to conclude on a remaining linear structure even after filtering.

The pairwise implementation of the Granger tests after VAR filtering, shows that the linear causal relationships detected on the raw returns have now disappeared. In fact none of the previously mentioned causalities or any other new ones have emerged after linear filtering. Similarly, no significant causal relationship could be detected after sixvariate VAR filtering, with the exception of two linkages, namely $\mathrm{GBP} / \mathrm{USD} \rightarrow \mathrm{EUR} / \mathrm{USD}$ and USD/CHF $\rightarrow$ EUR/USD both in Period I. The application of 
the Diks-Panchenko test on the VAR residuals points roughly towards the preservation of the results reported for the raw returns in the pairwise and six-variate implementation. Comparing the summary results in Table 3 , it is interesting to see that they show identical significant causal nonlinear relationships, except for the absence now of causality $\mathrm{GBP} / \mathrm{USD} \rightarrow \mathrm{EUR} / \mathrm{USD}$ in PII and the emergence of the unidirectional causality $\mathrm{USD} / \mathrm{CHF} \rightarrow \mathrm{USD} / \mathrm{JPY}$ in PI. In the six-variate representation (Table 4) the causal relationship USD/JPY $\rightarrow$ EUR/USD has vanished and the same applies to the unidirectional linkage USD/CAD $\rightarrow \mathrm{USD} / \mathrm{JPY}$. The nature and source of the detected nonlinearities are different from that of the linear Granger causality test and may also imply a temporary, or long-term, causal relationship between the currencies. For instance, exchange rate volatility might induce nonlinear causality. Given the status of the USD as the anchor currency, an innovation in US stock markets or an increase in the interest rates from the Federal Reserve System in the USA etc., may seriously affect the extent of dependency and volatility spillovers across currencies. The nature of the volatility transmission mechanism can be investigated after controlling for conditional heteroskedasticity using a GARCH-BEKK model, pairwise and in a six-variate representation. This approach allows the entire variance-covariance structure of the currency interrelationship to be incorporated.

\subsection{Causality testing on GARCH-BEKK filtered VAR-residuals}

The use of the Diks-Panchenko test on filtered data with a multivariate GARCH model enables one to determine whether the posited model is sufficient to describe the relationship among the series. If the statistical evidence of nonlinear Granger causality 
lies in the conditional variances and covariances then it would be strongly reduced when the appropriate multivariate GARCH model is fitted to the raw or linearly filtered data. However, failure to accept the no-causality null hypothesis may also constitute evidence that the selected multivariate GARCH model was incorrectly specified. This line of analysis is similar to the use of the univariate BDS test on raw data and on GARCH models (Brock et al., 1996; Brooks, 1996; Hsieh, 1989). Many GARCH models can be used for this purpose. In the present study the GARCH-BEKK model of Engle and Kroner (1995) is used. The BEKK $(p, q)$ model is defined as:

$$
\mathbf{H}_{t}=\mathbf{C}^{\prime} \mathbf{C}+\sum_{j=1}^{q} \mathbf{A}_{\mathbf{j k}}^{\prime} \boldsymbol{\varepsilon}_{\mathbf{t}-\mathbf{j}} \boldsymbol{\varepsilon}_{\mathbf{t}-\mathbf{j}}^{\prime} \mathbf{A}_{\mathbf{j k}}+\sum_{j=1}^{p} \mathbf{G}_{\mathbf{j} \mathbf{k}}^{\prime} \mathbf{H}_{\mathbf{t}-\mathbf{j}} \mathbf{G}_{\mathbf{j k}} \quad, \quad \boldsymbol{\varepsilon}_{\mathbf{t}}=\mathbf{H}_{\mathbf{t}}^{\mathbf{1 / 2}} \mathbf{v}_{\mathbf{t}}
$$

where $\mathbf{C}, \mathbf{A}_{\mathbf{j k}}$ and $\mathbf{G}_{\mathbf{j k}}$ are $(N x N)$ matrices and $\mathbf{C}$ is upper triangular. $\mathbf{H}_{\mathbf{t}}$ is the conditional covariance matrix of $\left\{\varepsilon_{t}\right\}$ with $\varepsilon_{t} \mid \Phi_{t-1} \sim\left(\mathbf{0}, \mathbf{H}_{\mathbf{t}}\right)$ and $\Phi_{t-1}$ the information set at time $t-1$. The residuals are obtained by the whitening matrix transformation $\mathbf{H}^{1 / 2} \boldsymbol{\varepsilon}_{\mathbf{t}}$. Gourieroux (1997) gives sufficient conditions for $\mathbf{A}_{\mathbf{t}}$ and $\mathbf{G}_{\mathbf{t}}$ in order to guarantee that $\mathbf{H}_{\mathbf{t}}$ is always positive definite.

Tables 3 and 4 show results before and after GARCH-BEKK $(1,1)$ filtering. The order parameters were determined for the time series in terms of the minimal SIC. The linear Granger causality interdependencies remain mostly absent exactly as after VAR filtering in both periods and for both representations i.e., pairwise and six-variate. One conclusion after the nonlinear causality testing is that in some cases the statistical significance is weaker after filtering than before. These differences in statistical significance indicate that the nonlinear causality is largely due to simple volatility effects. However, this is not indicative of a general conclusion. Instead, significant nonlinear 
interdependencies remain after the pairwise and six-variate GARCH-BEKK filtering revealing that volatility effects and spillovers are probably not the only ones inducing nonlinear causality. This of course does not apply to all the pairs of FX rates but some main results can be drawn for specific relationships. These are also depicted graphically in Figure 2 where strong causality (“**”) is denoted by a "double arrow”. In particular, the pairwise nonlinear causality reveals the unidirectional linkages $\mathrm{USD} / \mathrm{JPY} \rightarrow \mathrm{EUR} / \mathrm{USD}, \quad \mathrm{USD} / \mathrm{CHF} \rightarrow \mathrm{EUR} / \mathrm{USD}, \quad \mathrm{GBP} / \mathrm{USD} \rightarrow \mathrm{EUR} / \mathrm{USD} \quad$ and $\mathrm{AUD} / \mathrm{USD} \rightarrow \mathrm{USD} / \mathrm{CAD}$ in $\mathrm{PI}$, while in $\mathrm{PII}, \quad \mathrm{USD} / \mathrm{JPY} \rightarrow \mathrm{EUR} / \mathrm{USD}$ and $\mathrm{USD} / \mathrm{CHF} \rightarrow \mathrm{EUR} / \mathrm{USD}$ remain and $\mathrm{AUD} / \mathrm{USD} \rightarrow \mathrm{EUR} / \mathrm{USD}$ is added. Thus, there is strong evidence of the influence of the aforementioned currencies on EUR/USD though some in pre- and others in post-crisis period. This is perhaps an after-effect of the independent and robust Euro zone behavior against the USD (Bénassy-Quéré et. al., 2000; Yang, 2005). A potential increase/decrease in the US dollar volatility affects the Euro zone currencies less than (and with a significant delay) the USD closest dependent economies of Canada and Australia.

Now, incorporating the effect of all the currencies in a six-variate GARCH-BEKK framework, the "whitened" residuals present different causal relationships than before. Specifically, in PI two bidirectional linkages exist, namely GBP/USD EUR/USD and $\mathrm{EUR} / \mathrm{USD} \leftrightarrow \mathrm{USD} / \mathrm{CAD}$ and two unidirectional relationships USD/CHF $\rightarrow \mathrm{EUR} / \mathrm{USD}$, $\mathrm{USD} / \mathrm{CAD} \rightarrow \mathrm{USD} / \mathrm{JPY}$. In PII, besides the causal linkage of GBP/USD $\rightarrow$ EUR/USD, the influence of USD/CAD is strongly evident in forming the unidirectional relationships, i.e., $\mathrm{USD} / \mathrm{CAD} \rightarrow \mathrm{AUD} / \mathrm{USD}, \quad \mathrm{USD} / \mathrm{CAD} \rightarrow \mathrm{USD} / \mathrm{CHF}, \quad \mathrm{USD} / \mathrm{CAD} \rightarrow \mathrm{EUR} / \mathrm{USD} \quad$ and $\mathrm{USD} / \mathrm{CAD} \rightarrow \mathrm{GBP} / \mathrm{USD}$. A possible explanation is that Canadian market acting as a 
proxy for the neighboring US stock, bond or currency market reacts faster to any innovation or volatility jumps (Yang, 2005; Bessler et. al., 2003; Eun, 1989). Finally, in all results, third moment causality may be also a significant factor of the remaining interdependence.

\section{Conclusions}

In the present study we investigated the existence of linear and nonlinear causal relationships among the most liquid and widely traded currency pairs in the world, namely EUR/USD, GBP/USD, USD/JPY, USD/CHF, AUD/USD and USD/CAD. Several interesting conclusions have already emerged from this study. In particular, it was shown that almost all FX markets considered here have become more internationally integrated after the Asian financial crisis. Additionally, whilst the linear causal relationships detected on the returns have disappeared after proper filtering, nonlinear causal linkages in some cases emerged and more importantly persisted even after GARCH filtering during both the pre- and post-Asian financial crisis period. For instance, there is strong evidence of the influence of the other currencies on EUR/USD and that Canadian currency market substituting for US financial market nonlinearly causes the other currency markets beyond the conventional spillover effect. These results, apart from offering a much better understanding of the dynamic linear and nonlinear relationships underlying the major currency markets, may have important implications for market efficiency. For instance, they may be useful in future research to quantify the process of financial integration or may influence the greater predictability of these markets. 
An interesting subject for future research is the nature and source of the nonlinear causal linkages. As was shown, volatility effects might partly induce nonlinear causality. The fitted GARCH-BEKK models account for a large part of the nonlinearity in daily exchange rates, but only in some cases. Perhaps other models of short-term exchange-rate determination should be developed to explain this stylized fact. Moreover, currency returns may exhibit statistically significant higher-order moments. This may explain why GARCH filtering does not capture all the nonlinearity in currency returns. A similar result was reported in Scheinkman, J., and LeBaron, (1989) for stock returns. Finally, alternative parameterized asymmetric multivariate GARCH models could be employed. These models would accommodate the asymmetric impact of unconditional shocks on the conditional variances. 


\section{References}

Baek, E., and Brock, W., 1992. A general test for non-linear Granger causality: bivariate model. Working paper, Iowa State University and University of Wisconsin, Madison, WI. Baillie, R., Bollerslev, T.P., 1989. The message in daily exchange rates: a conditional variance tale. Journal of Business and Economic Statistics 7, 297-305. , 1990. Intra-day and intra-market volatility in foreign

exchange rates. Review of Economic Studies 58, 565-585.

Bénassy-Quéré A. and Lahrèche-Révil A., 2000. The Euro as a Monetary Anchor in the CEECs, Open Economies Review 11 (4), 303-321

Bessler, D.A. and Yang, J., 2003. The structure of interdependence in international stock markets. Journal of International Money and Finance 22, 261-287.

Black, F., 1986. Noise. Journal of Finance 41, 529-543.

Blanchard, O., Watson, M.W., 1982. Bubbles, rational expectations, and financial markets. In: Wachtel, P. (Ed.) Crises in the economic and financial structure. Lexington Books, Lexington, MA.

Boothe, P., Glassman, D., 1987. The statistical distribution of exchange rates. Journal of International Economics 22, 297-319.

Brock, W.A., Dechert, W.D., Scheinkman, J.A., LeBaron, B., 1996. A test for independence based on the correlation dimension. Econ. Rev. 15(3), 197-235.

Brooks, C., 1996. Testing for nonlinearities in daily pound exchange rates. Applied Financial Economics 6, 307-317.

De Long, J.B., Shleifer, A., Summers, L.H., Waldmann, R.J., 1990. Noise trader risk in financial markets. Journal of Political Economy 98, 703-738. 
Diks, C. and Panchenko, V., 2005. A note on the Hiemstra-Jones test for Granger noncausality. Studies in Nonlinear Dynamics and Econometrics 9, art. 4 2006. A new statistic and practical guidelines for nonparametric Granger causality testing. Journal of Economic Dynamics \& Control 30, $1647-1669$.

Engle, R.F., 1982. Autoregressive conditional heteroscedasticity with estimates of the variance of United Kingdom inflation. Econometrica 50, 987-1008.

Engle, R.F., Bollerslev, T., 1986. Modelling the persistence of conditional variances. Econometric Reviews 5, 1-50.

Engle, R.F., Ito, T., Lin, W.-L., 1990. Meteor showers or heat waves. Heteroskedastic intra-daily volatility in the foreign exchange market. Econometrica 55, 525-542.

Engle, R.F. and Kroner, F.K. 1995. Multivariate simultaneous generalized ARCH. Econometric Theory, 11, 122-150.

Eun, C. and Shim, S., 1989. International transmission of stock market movements. Journal Financial and Quantitative Analysis, 24 241-256

Flood, R.P., Garber, P.M., 1980. Market fundamentals versus price-level bubbles: the first tests. Journal of Political Economy 88, 745-770.

Flood, R.P., Isard, P., 1989. Monetary policy strategies, IMF Staff Papers 36, 612-632.

Flood, R.P., Rose, A.K., Mathieson, D., 1991. An empirical exploration of exchange-rate target-zones. Carnegie-Rochester Conference Series on Public Policy 35, 7-66.

Flood, R.P., Rose, A.K., 1995. Fixing exchange rates: a virtual quest for fundamentals. Journal of Monetary Economics 36, 3-37. 
Frankel, J.A., Froot, K.A., 1986. The dollar as a speculative bubble: a tale of fundamentalists and chartists, National Bureau of Economic Research Working Paper No. 1854, March.

Froot, K.A., Obstfeld, M., 1991. Intrinsic bubbles: the case of stock prices. American Economic Review 81, 1189-1214.

Granger, C.W.J. 1969. Investigating causal relations by econometric models and crossspectral methods. Econometrica 37, 424-438.

Gourieroux, C. 1997. ARCH models and Financial applications. Springer Verlag

Hiemstra, C. and Jones, J.D., 1994. Testing for linear and nonlinear Granger causality in the stock price-volume relation. Journal of Finance 49, 1639-1664.

Hogan, W.P., Sharpe, I.G., 1984. On the relationship between the New York closing spot U.S.\$ $\$$ Australian exchange rate and the reserve bank of Australia's official rate. Economics Letters 14, 73-79

Hsieh, D., 1989. Modeling heteroscedasticity in daily foreign exchange rates. Journal of Business and Economic Statistics 7, 307-317.

Ito, T., Roley, V.V., 1987. News from the US and Japan, which moves the yen/dollar exchange rate. Journal of Monetary Economics 19, 225-278.

Koutmos, G., Booth, G.G., 1995. Asymmetric volatility transmission in international stock markets. Journal of International Money and Finance 14, 747-762.

Krugman, P., 1991. Target zones and exchange rate dynamics. Quarterly Journal of Economics 106, 669-682.

Krugman, P., Miller, M., 1993. Why have a target zone? Canegie-Rochester Conference Series on Public Policy 38, 279-314. 
Kyle, A.S., 1985. Continuous auctions and insider trading. Econometrica 53, 1335-1355.

Laopodis, N., 1997. US dollar asymmetry and exchange rate volatility. Journal of Applied Business Research 13 (2), 1-8.

,1998. Asymmetric volatility spillovers in deutsche mark exchange rates.

Journal of Multinational Financial Management 8, 413-430

Lindberg, H., Soderlind, P., 1994. Testing the basic target zone models on the Swedish data 1982-1990. European Economic Review 38, 1441-1469.

Ma Y., Kanas A., 2000. Testing for a nonlinear relationship among fundamentals and exchange rates in the ERM. Journal of International Money and Finance 19, 135-152

Meese, R.A., Rogoff, K., 1983. Empirical exchange rate models of the seventies: do they fit out of sample? Journal of International Economics 14, 3-24.

Meese, R.A., Rose, A.K., 1990. Nonlinear, nonparametric, nonessential exchange rate estimation. American Economic Review 80, 192-196.

Rose, A.K., 1996. Explaining exchange rate volatility: an empirical analysis of "the holy trinity" of monetary independence, fixed exchange rates, and capital mobility. Journal of International Money and Finance 15, 925-945.

Scheinkman, J., and LeBaron, 1989. Nonlinear Dynamics and Stock Returns. The Journal of Business 62 (3), 311-337.

Shiller, R.J., 1984. Stock prices and social dynamics. Brookings Papers on Economic Activity (2), 457-498.

Summers, L.H., 1986. Does the stock market rationally reflect fundamental values? Journal of Finance 41, 591-601. 
Yang J., 2005. International bond market linkages: a structural VAR analysis. Journal of International Financial Markets, Institutions and Money 15, 39-54 
Figure 1: FX time series in PI: 3/20/1991 - 3/20/1997 and PII: 3/20/2003 - 3/20/2007

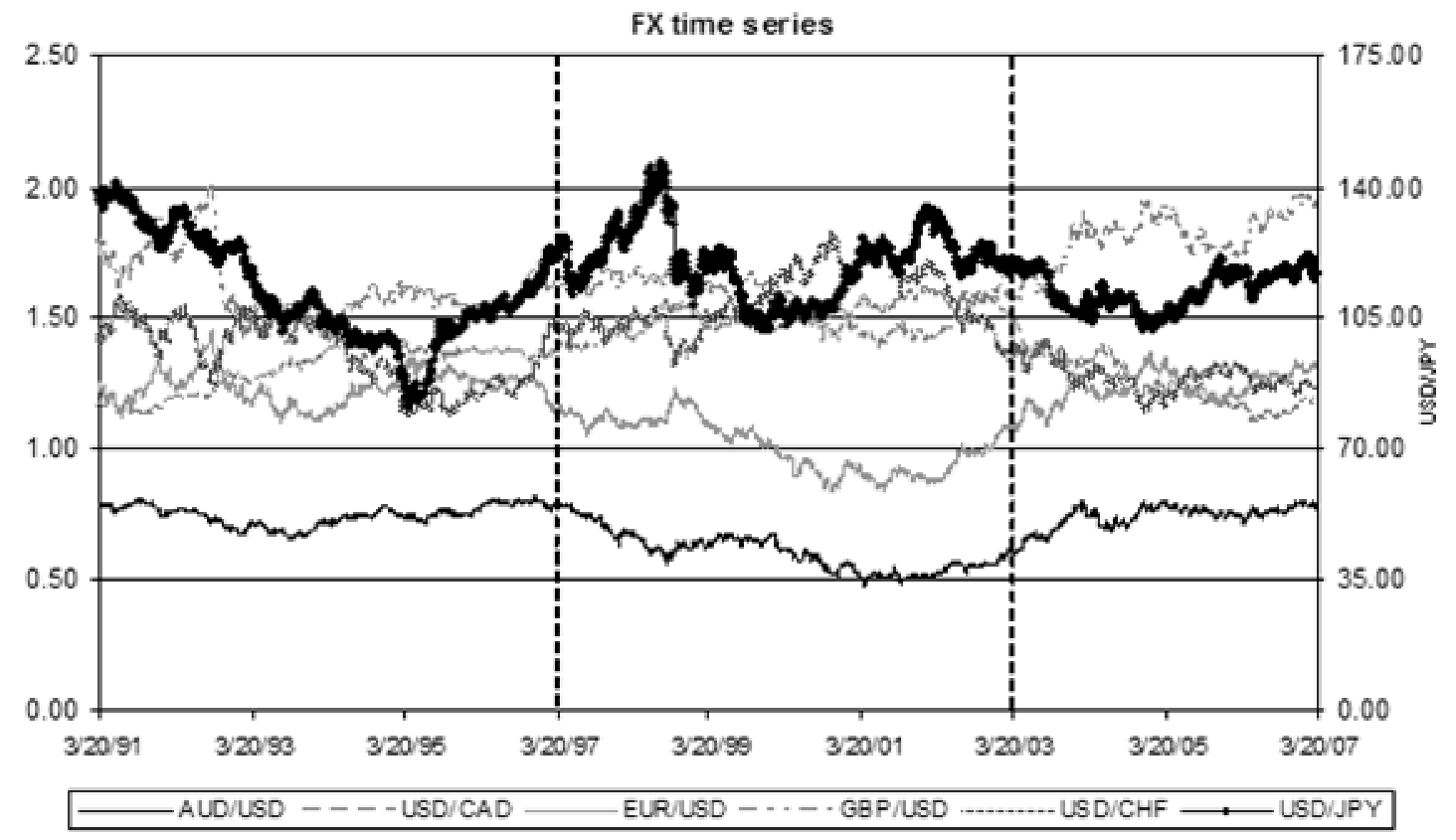


Figure 2: Diagrammatical representation of directional causalities on GARCH-BEKK filtered VAR residuals (Diks-Panchenko test)

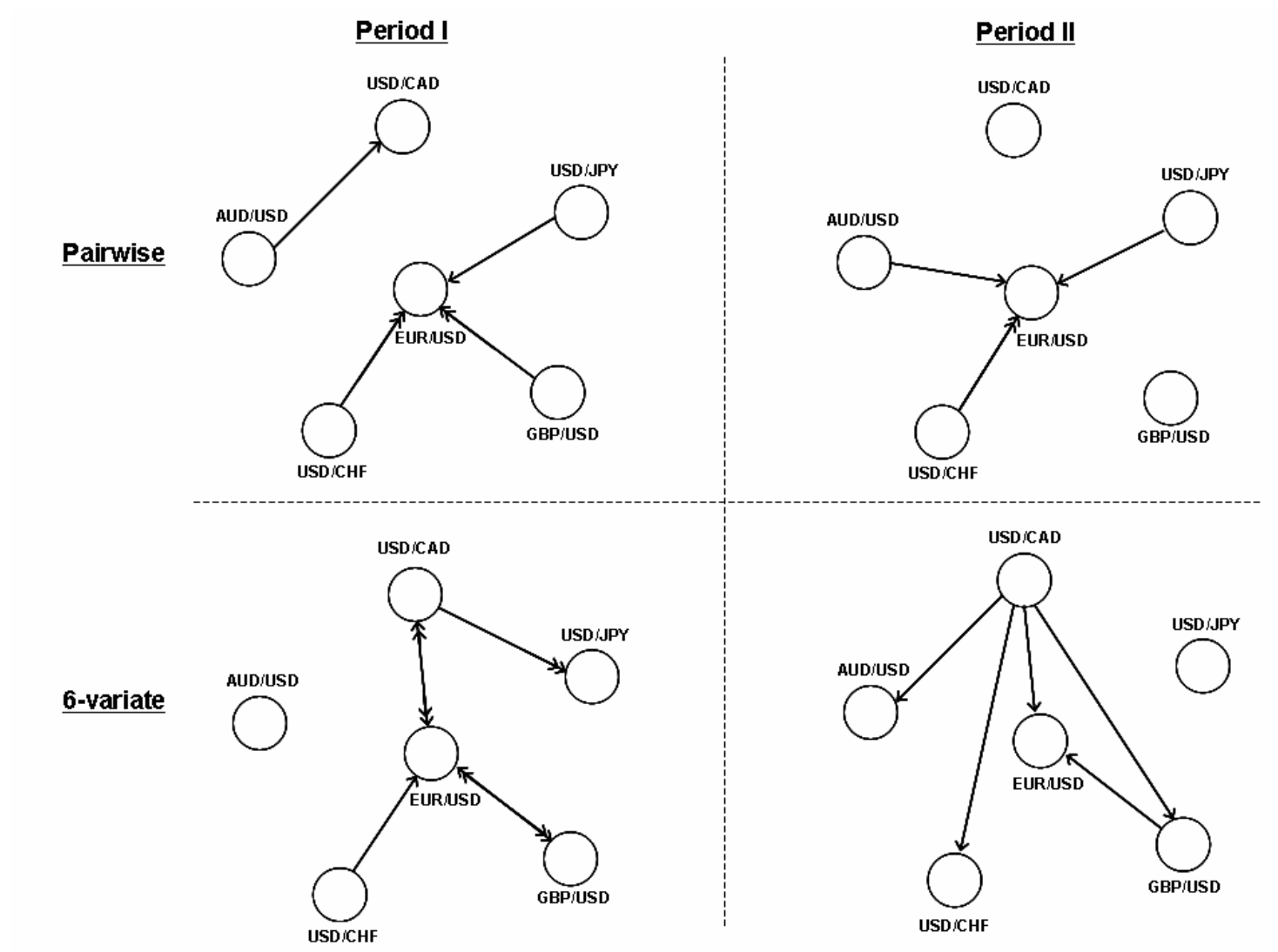

$\begin{aligned} \text { Notation: } & \longrightarrow \longleftrightarrow \text { denote unidirectional and bi-directional causality corresponding to } 5 \% \leq p \text {-value }<1 \% \\ & \longrightarrow \longleftrightarrow \text { denote unidirectional and bi-directional causality corresponding to } p \text {-value } \leq 1 \%\end{aligned}$ 
Table 1: Descriptive Statistics

Period I (3/20/1991-3/20/1997)

\begin{tabular}{|l|r|r|r|r|r|r|}
\hline \hline & AUD/USD & USD/CAD & EUR/USD & GBP/USD & USD/CHF & USD/JPY \\
\hline Mean & $1.47 \mathrm{E}-05$ & 0.000113 & $-4.8 \mathrm{E}-05$ & $-7.1 \mathrm{E}-05$ & $1.6 \mathrm{E}-05$ & $-6.9 \mathrm{E}-05$ \\
\hline Standard Deviation & 0.004764 & 0.002721 & 0.006599 & 0.006731 & 0.007806 & 0.006674 \\
\hline Sample Variance & $2.27 \mathrm{E}-05$ & $7.4 \mathrm{E}-06$ & $4.35 \mathrm{E}-05$ & $4.53 \mathrm{E}-05$ & $6.09 \mathrm{E}-05$ & $4.45 \mathrm{E}-05$ \\
\hline Kurtosis & 1.702 & 2.265 & 4.665 & 4.032 & 2.422 & 8.091 \\
\hline Skewness & -0.303 & 0.070 & -0.307 & -0.274 & -0.049 & -0.693 \\
\hline Correlation Matrix & & & & & & \\
\hline & AUD/USD & \multicolumn{1}{|c|}{ USD/CAD } & EUR/USD & GBP/USD & USD/CHF & USD/JPY \\
\hline AUD/USD & 1 & & & & & \\
\hline USD/CAD & -0.166 & 1 & & & & \\
\hline EUR/USD & -0.004 & 0.010 & 1 & & & \\
\hline GBP/USD & 0.088 & -0.008 & 0.600 & & & \\
\hline USD/CHF & 0.023 & -0.082 & -0.659 & -0.717 & & 1 \\
\hline USD/JPY & 0.108 & -0.154 & -0.345 & -0.408 & 0.565 & \\
\hline
\end{tabular}

Period II (3/20/2003-3/20/2007)

\begin{tabular}{|l|r|r|r|r|r|r|}
\hline \hline & \multicolumn{1}{|c|}{ AUD/USD } & USD/CAD & EUR/USD & GBP/USD & USD/CHF & USD/JPY \\
\hline Mean & 0.000294 & -0.00023 & 0.000218 & 0.000216 & -0.00013 & $-2.4 \mathrm{E}-05$ \\
\hline Standard Deviation & 0.006549 & 0.005063 & 0.005597 & 0.005368 & 0.006582 & 0.005423 \\
\hline Sample Variance & $4.29 \mathrm{E}-05$ & $2.56 \mathrm{E}-05$ & $3.13 \mathrm{E}-05$ & $2.88 \mathrm{E}-05$ & $4.33 \mathrm{E}-05$ & $2.94 \mathrm{E}-05$ \\
\hline Kurtosis & 1.168 & 0.520 & 0.399 & 0.570 & 0.765 & 1.016 \\
\hline Skewness & -0.430 & 0.049 & 0.002 & -0.077 & -0.183 & -0.174 \\
\hline Correlation Matrix & & & & & & \\
\hline & AUD/USD & \multicolumn{1}{|c|}{ USD/CAD } & EUR/USD & GBP/USD & USD/CHF & USD/JPY \\
\hline AUD/USD & 1 & & & & & \\
\hline USD/CAD & -0.538 & 1 & & & & \\
\hline EUR/USD & 0.567 & -0.407 & 1 & & & \\
\hline GBP/USD & 0.647 & -0.443 & 0.647 & & & \\
\hline USD/CHF & -0.608 & 0.460 & -0.752 & -0.757 & & \\
\hline USD/JPY & -0.514 & 0.319 & -0.444 & -0.487 & 0.544 & \\
\hline
\end{tabular}


Table 2: Unit root tests

\begin{tabular}{|c|c|c|}
\hline Variables & ADF-statistic (PI) & ADF-statistic (PII) \\
\hline EUR/USD (0) & 0.179 & 0.081 \\
\hline$r_{\text {EURIUSD }}(0)$ & $0.000^{\star *}$ & $0.000^{\star \star}$ \\
\hline GBP/USD (0) & 0.207 & 0.242 \\
\hline$r_{\text {GBP/USD }}(0)$ & $0.000^{\star \star}$ & $0.000^{* *}$ \\
\hline USD/JPY (0) & 0.505 & 0.268 \\
\hline$r_{\text {USD/JPY }}(0)$ & $0.000^{\star \star}$ & $0.000^{\star \star}$ \\
\hline USD/CHF (0) & 0.491 & 0.070 \\
\hline $\mathrm{r}$ USD/CHF (0) & $0.000^{\star \star}$ & $0.000^{\star *}$ \\
\hline AUD/USD (0) & 0.451 & 0.023 \\
\hline$r_{\text {AUD/USD }}(0)$ & $0.000^{\star \star}$ & $0.000^{* *}$ \\
\hline USD/CAD (0) & 0.595 & 0.204 \\
\hline (0) & $0.000^{\star *}$ & $0.000^{* *}$ \\
\hline
\end{tabular}

All variables are in logarithms and reported numbers are $p$-values. The number of lags in parenthesis is selected using the SIC. $(* *)$ denotes $p$-value corresponding to $99 \%$ confidence level. 


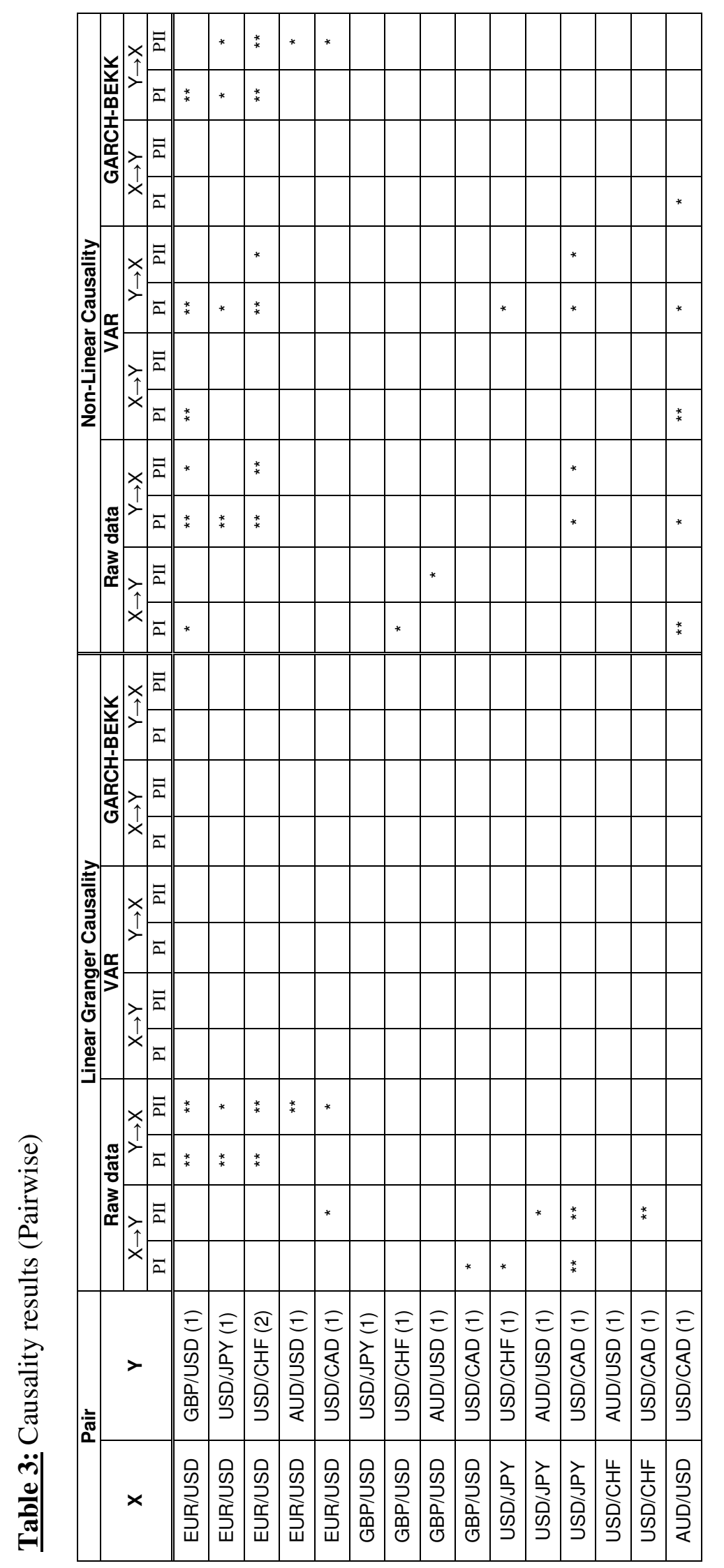

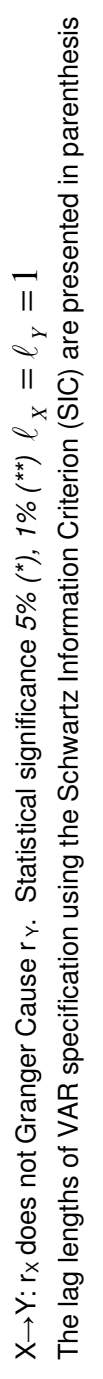




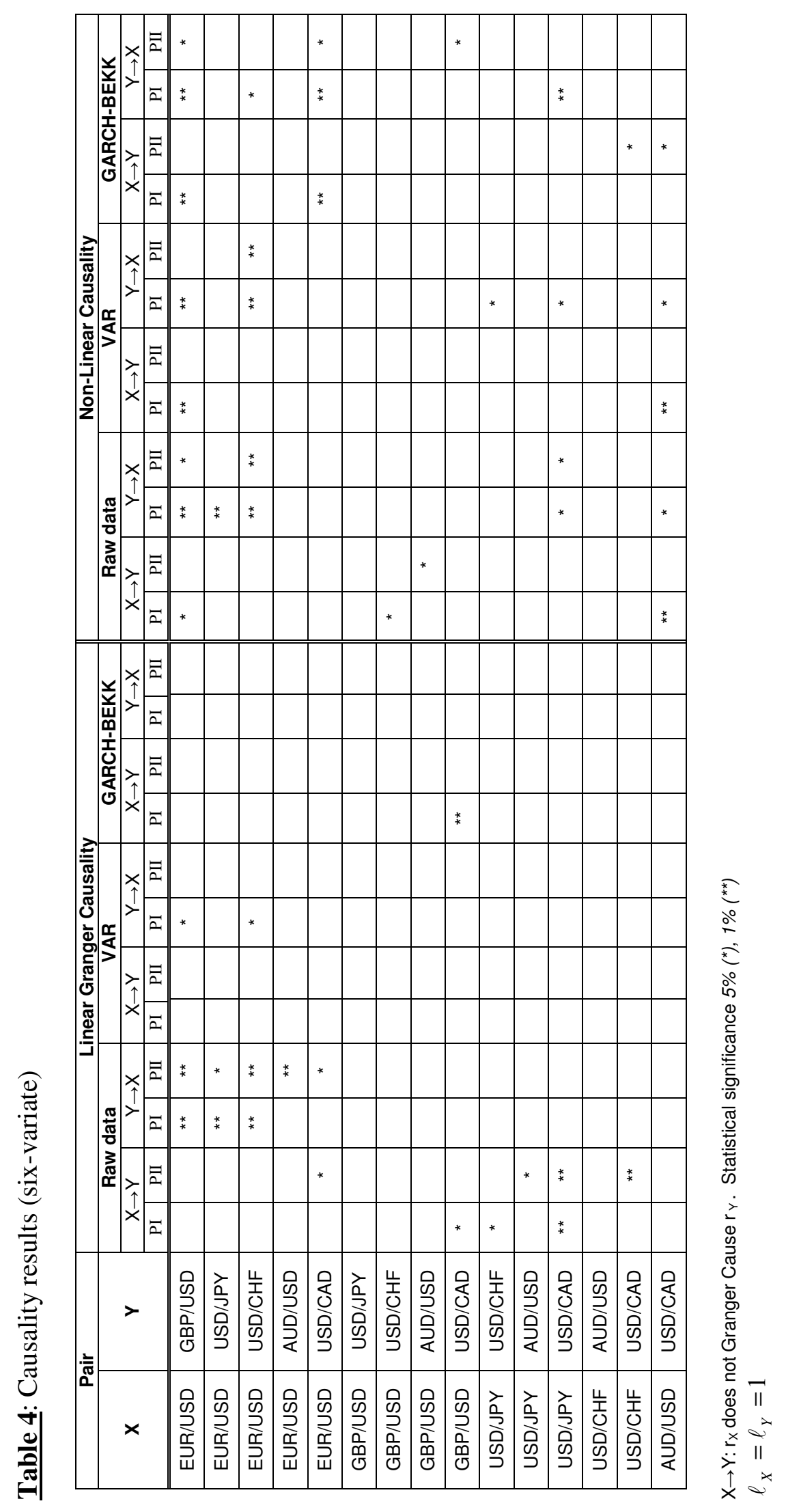

